\title{
Erector spinae plane catheter for neonatal thoracotomy: a potentially safer alternative to a thoracic epidural
}

\author{
Adam C. Adler, MS, MD, FAAP, FASE (1) - Michael M. Yim, MD • \\ Arvind Chandrakantan, MD, MBA, FAAP, FASA
}

Received: 3 January 2019/Revised: 4 January 2019/Accepted: 5 January 2019/Published online: 17 January 2019

(C) Canadian Anesthesiologists' Society 2019

A three-week-old 4-kg neonate required thoracotomy for excision of the right lower lobe to remove a large congenital cystic adenomatoid malformation. An erector spinae plane block (ESPB) was used for postoperative analgesia and was performed in the lateral position (after the surgeon had marked the incision site). An 18G 50-mm Tuohy needle (Pajunk, Geisinger, Germany) was inserted at approximately $\mathrm{T} 6$, and the erector spinae plane was hydro-dissected with saline under ultrasound guidance extending two vertebral spaces above and below the injection site (panels $\mathrm{A}$ and $\mathrm{B}$ in the figure); this was followed by placement of a 20G SonoLong catheter (Pajunk, Geisinger, Germany). Following completion of the surgery, the catheter was bolus with local anesthetic under ultrasound guidance, again confirming that it spread at least two segments craniocaudally above and below the incision and chest tube site (panel C). In addition to administration of oral acetaminophen $12.5 \mathrm{mg} \cdot \mathrm{kg}^{-1}$ every six hours, ropivacaine $0.1 \%\left(0.25 \mathrm{mg} \cdot \mathrm{kg}^{-1} \cdot \mathrm{hr}^{-1}\right)$ was infused via the ESPB catheter. The patient thus had excellent analgesia for the first $48 \mathrm{hr}$ postoperatively and required only a single dose of morphine $\left(0.1 \mathrm{mg} \cdot \mathrm{kg}^{-1}\right)$ on

\footnotetext{
A. C. Adler, MS, MD, FAAP, FASE ( $₫)$

Department of Anesthesiology, Perioperative and Pain Medicine,

Texas Children's Hospital, Baylor College of Medicine,

Houston, TX, USA

e-mail: adamcadler@gmail.com;

axadler@texaschildrens.org
}

Division of Cardiovascular Anesthesiology, Texas Children's Hospital, Baylor College of Medicine, Houston, TX, USA

M. M. Yim, MD - A. Chandrakantan, MD, MBA, FAAP, FASA Department of Anesthesiology, Perioperative and Pain Medicine, Texas Children's Hospital, Baylor College of Medicine,

Houston, TX, USA the day of surgery. The chest tube and ESPB catheter were removed on the second postoperative day without incident, and the patient was discharged on postoperative day 3.

Thoracotomy is associated with significant postoperative pain. Opioid-based analgesia has proved difficult, particularly due to the associated respiratory depression when used in neonates. Conversely, untreated pain results in inadequate ventilation, thereby increasing pulmonary morbidity. A traditional regional anesthesia approach for post-thoracotomy pain relies on a thoracic epidural. In children, the shorter distance from skin to the dura implies a significant risk to the spinal cord during epidural needle insertion. ${ }^{1}$ A potentially safer approach to the thoracic epidural space is via a caudally threaded epidural. However, recent studies suggest high rates of catheter migration in small children. ${ }^{2}$ The paravertebral block maintains a significant risk of damage to surrounding structures (e.g., spinal nerves, pneumothorax).

Erector spinae plane block is a relatively new block used to provide chest wall analgesia ${ }^{3}$ and has thus far displayed an excellent safety profile. ${ }^{3}$ Erector spinae plane block affords an excellent margin of safety because of its more superficial depth and greater distance from important structures (e.g., spinal cord, pleura). Coagulopathy should be a lesser contraindication given that the needle placement is a significant distance from the spinal cord and epidural venous plexus, a common source of epidural hematoma formation seen with thoracic epidural and paravertebral approaches. The potential risk of a pneumothorax from an ESPB is additionally offset, specifically during thoracotomy, by the intentional surgical exploration of the lung and planned chest tube insertion. Thus, the ESPB is a potentially reliable, safe alternative to epidural and paravertebral catheters and should be considered for chest wall surgery, particularly in neonates. 

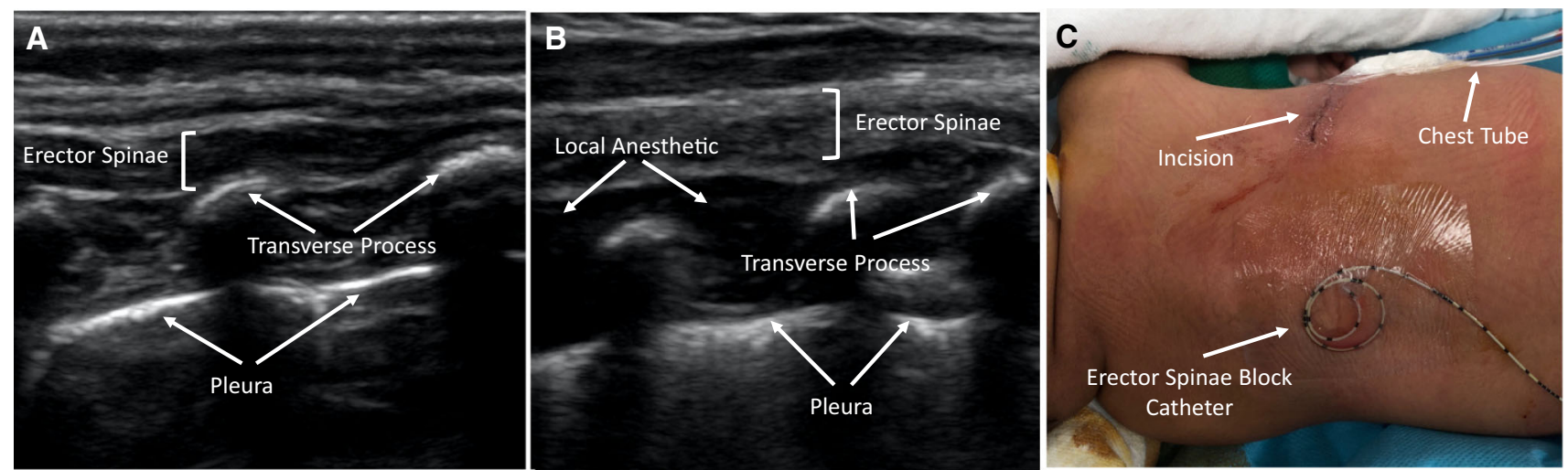

Figure A) Sonographic anatomy prior to establishing an erector spinae plane block. (ESPB). B) Imaging after the local anesthetic injection for the ESPB shows elevation of the erector spinae muscle

\section{Conflicts of interest None declared.}

Editorial responsibility This submission was handled by Dr. Hilary P. Grocott, Editor-in-Chief, Canadian Journal of Anesthesia.

\section{Funding None.}

\section{References}

1. Wood CE, Goresky GV, Klassen KA, Kuwahara B, Neil SG. Complications of continuous epidural infusions for postoperative analgesia in children. Can J Anaesth 1994; 41: 613-20. off the transverse process. C) Erector spinae plane block catheter and patient position relative to the surgical incision and chest tube site.

2. Simpao AF, Gálvez JA, Wartman EC, et al. The migration of caudally threaded thoracic epidural catheters in neonates and infants. Anesth Analg 2018; DOI: https://doi.org/10.1213/ane. 0000000000003311.

3. Muñoz F, Cubillos J, Bonilla AJ, Chin KJ. Erector spinae plane block for postoperative analgesia in pediatric oncological thoracic surgery. Can J Anesth 2017; 64: 880-2.

Publisher's Note Springer Nature remains neutral with regard to jurisdictional claims in published maps and institutional affiliations. 